\title{
PERBEDAAN HASIL BELAJAR SISWA MENGGUNAKAN MEDIA AUGMENTED REALITY DENGAN MEDIA GAMBAR PADA TEMA 7 SUBTEMA 1 KELAS I MIN 3 KOTA MEDAN
}

\author{
Robenhart Tamba, Devi Fatia \\ Surel: robenhart@gmail.com
}

\begin{abstract}
This study aims to determine the differences in the learning outcomes of junior high school students in Medan City for the 2019/2020 fiscal year 2019/2020 in the use of augmented reality media and image media on the sub-topic 7. 1) Living and non-living objects around us Level I MIN 3 This type of research is a quasi-experimental research. This research was conducted in MIN 3 Medan City. The population in this study were all 50 students of class 1 MIN 3 Medan. The sample includes 2 classes, namely class Ia with 25 students in experimental class II, and class Ib in experimental class I with 25 students. Data collection techniques in this study using observation and tests. The data analysis technique used normality, homogeneity, and hypothesis testing. The results of this study indicate that the average value of the Type I Experiment before treatment was 47.4, and after receiving augmented reality treatment the average value increased to 91.4. The average score of class II experimental students before treatment was 46.4, increasing to 78.6 after treatment. After knowing the mean, standard deviation, and variance of the various data, the significance level of the hypothesis results obtained using the test is 0.05 to 7.009 , and the t table is 1.676.
\end{abstract}

Keywords: Augmented Reality Media, Media Images, Learning Outcomes

\begin{abstract}
ABSTRAK
Penelitian ini bertujuan untuk mengetahui perbedaan hasil belajar siswa SMP di Kota Medan tahun anggaran 2019/2020 tahun anggaran 2019/2020 dalam penggunaan media augmented reality dan media gambar pada subtema topik 7. 1) Benda hidup dan tak hidup di sekitar kita Level I MIN 3. Jenis penelitian ini adalah penelitian eksperimen semu. Penelitian ini dilakukan di MIN 3 Kota Medan. Populasi dalam penelitian ini adalah seluruh 50 siswa kelas 1 MIN 3 Kota Medan. Sampel meliputi 2 kelas yaitu kelas Ia sebanyak 25 siswa kelas eksperimen II, dan kelas Ib kelas eksperimen I sebanyak 25 siswa. Teknik pengumpulan data dalam penelitian ini menggunakan observasi dan tes. Teknik analisis data menggunakan normalitas, homogenitas, dan pengujian hipotesis. Hasil penelitian ini menunjukkan bahwa nilai rata-rata Eksperimen Tipe I sebelum perlakuan adalah 47,4, dan setelah mendapat perlakuan augmented reality nilai ratarata meningkat menjadi 91,4. Nilai rata-rata siswa kelas II eksperimen sebelum perlakuan adalah 46,4 meningkat menjadi 78,6 setelah perlakuan. Setelah diketahui mean, standar deviasi, dan varians dari berbagai data, maka tingkat signifikansi hasil hipotesis yang diperoleh dengan menggunakan uji t adalah 0,05 sampai 7,009, dan t tabel sebesar 1,676.
\end{abstract}

Kata Kunci: Media Augmented Reality, Media Gambar, Hasil Belajar 


\section{PENDAHULUAN}

Pembelajaran adalah proses penyesuaian lingkungan sekitar siswa untuk mendorong mereka tumbuh dan melakukan proses belajar. UndangUndang Republik Indonesia Nomor 20 Tahun 2003 tentang Sistem Pendidikan Nasional menyatakan bahwa 'belajar adalah proses interaksi antara pendidik dan peserta didik dan sumber belajar yang berlangsung di lingkungan belajar" dengan kata lain rangkaian kegiatan. untuk mempelajari. Hal ini terkait dengan kegiatan belajar mengajar yang melibatkan guru dan siswa sehingga mereka dapat mengalami perubahan positif dalam diri mereka dan pada akhirnya mencapai tujuan belajarnya dalam bidang pengetahuan, sikap dan keterampilan.

Menurut Sabri (2010: 1) menyatakan "strategi pembelajaran adalah upaya guru dalam menciptakan suatu sistem lingkungan yang memungkinkan terjadinya proses mengajar agar tujuan pembelajaran yang telah dirumuskan dapat tercapai dan berhasil guna". Dengan kata lain, strategi pembelajaran tepat untuk membantu guru menentukan berbagai kegiatan yang berkaitan dengan proses belajar mengajar, mempersiapkan semua elemen kunci pembelajaran, dan membantu siswa mencapai tujuan pembelajarannya. Ada lima elemen penting dalam sebuah strategi pembelajaran. Komponen tersebut salah satunya adalah media pembelajaran. Gagne dan Briggs
(Arsyad, 2017: 4) menyatakan "media pembelajaran meliputi alat yang secara fisik digunakan untuk menyampaikan isi materi pengajaran, yang terdiri dari buku, tape recorder, kaset, video kamera, video recorder, film, slide”. Dengan kata lain, media ajar adalah alat yang dapat menyampaikan pesan kepada siswa berupa bahan ajar sehingga dapat memusatkan pikiran, perhatian, dan minat siswa pada proses pembelajaran.

Guru dituntut kreatif dan inovatif dalam penggunaan media pembelajaran agar tujuan pembelajaran dapat dicapai dengan mudah sehingga siswa mendapatkan hasil belajar yang memuaskan. Dari hasil observasi di MIN 3 Kota Medan masih ditemukannya beberapa masalah antara lain : pertama, guru tidak selalu menggunakan media pembelajaran saat melakukan kegiatan belajar mengajar. Kedua, guru menggunakan media pembelajaran hanya dari lingkungan sekolah saja. Kelemahan dari penggunaan media ini yaitu tidak semua objek yang dibutuhkan berada di lingkungan sekolah. Ketiga, guru mendominasi kegiatan belajar mengajar dengan konvensional (ceramah). Guru dituntut untuk kreatif dan inovatif dalam penggunaan alat peraga agar tujuan pembelajaran dapat dengan mudah dicapai dan siswa memperoleh hasil belajar yang memuaskan. Pengamatan di MIN 3 Kota Medan mengungkapkan beberapa permasalahan, antara lain: 
Pertama, guru tidak selalu menggunakan bahan ajar dalam kegiatan belajar mengajar. Kedua, guru hanya menggunakan alat peraga dari lingkungan sekolah. Kelemahan penggunaan media ini adalah tidak semua barang yang dibutuhkan ada di lingkungan sekolah. Ketiga, guru mendominasi kegiatan pendidikan dan metodologis (ceramah). Tiga masalah yang ditemukan selama observasi sangat mempengaruhi lingkungan belajar siswa. Siswa kurang termotivasi dan kurang aktif dalam mengikuti kegiatan belajar mengajar. Akibat kondisi kelas yang kurang kondusif, siswa memiliki pemahaman yang kurang baik terhadap materi ajar, yang sangat mempengaruhi hasil belajarnya.

Pada tema 7 subtema 1 2018/2019 nilai ulangan harian 23 siswa kelas IA dan 23 siswa kelas IB memiliki nilai KKM 75. Ditemukan 13 siswa kelas IA tidak tuntas dan 10 siswa yang sudah selesai. Kelas IB ditemukan 14 siswa tidak tuntas, dan 9 siswa tuntas. Jika demikian, 58,7\% atau sebanyak 27 siswa dari 46 siswa tidak mencapai KKM, dan 41,3\% atau sebanyak 19 siswa dari 46 siswa mencapai KKM. Dapat dikatakan bahwa nilai siswa di I MIN 3 Kota Medan tergolong rendah. Hal ini terjadi karena pengajaran guru yang monoton dan kurang kreatif dan inovatif dalam menyajikan materi pembelajaran. Bahan pembungkus yang kurang baik cepat membuat siswa bosan dalam kegiatan belajar, yang membuat pembelajaran menjadi tidak efektif karena siswa mencari kegiatan lain yang akan membebaskan mereka dari kegiatan guru yang monoton seperti bercerita dengan teman atau mengganggu teman. Hal ini menyebabkan siswa tidak dapat memahami materi secara optimal, yang berdampak besar pada hasil belajarnya. Oleh karena itu, media pembelajaran merupakan komponen yang berpengaruh besar terhadap hasil belajar siswa. Media harus mampu memusatkan pikiran, perhatian dan minat siswa pada proses belajar mengajar agar tercapai hasil belajar yang baik.

Salah satu upaya yang dapat digunakan untuk mengatasi permasalahan tersebut adalah penggunaan media berbasis augmented reality dan bergambar agar siswa lebih termotivasi dalam proses kegiatan belajar mengajar agar tercipta kegiatan belajar yang kondusif dan pada akhirnya memaksimalkan hasil belajar. Media berbasis augmented reality adalah teknologi yang menggabungkan dunia nyata dan dunia maya. Ronald $\mathrm{T}$. Azuma dalam (Munir, 2017: 93) mendefinisikan "augmented reality sebagai penggabungan benda-benda nyata dan maya dilingkungan nyata, berjalan secara interaktif dalam waktu nyata, dan terdapat integrasi antara benda dalam tiga dimensi, yaitu benda maya terintegrasi dalam dunia nyata". Dengan kata lain, augmented reality adalah teknologi yang dapat menggabungkan gambar 2D atau 3D dengan dunia nyata. Kelebihan media augmented reality adalah dapat memusatkan perhatian siswa, dan 
siswa dapat mengakses model dari perangkat setiap saat, yang dapat mengatasi keterbatasan pengamatan kita. Dan media gambar adalah jenis media yang menggambarkan informasi dalam dua dimensi. Kelebihan gambar adalah spesifik, dapat mengatasi keterbatasan ruang dan waktu, serta dapat mengatasi keterbatasan pengamatan kita.

\section{METODE PENELITIAN}

Penelitian ini menggunakan metode penelitian eksperimen dengan desain penelitian kuasi eksperimen. Jenis penelitian ini adalah penelitian komparasi. Menurut Arikunto (2013: 6) penelitian komparasi menunjukkan bahwa dalam penelitian ini bermaksud mengadakan perbandingan kondisi yang ada di dua tempat, apakah kedua kondisi tersebut sama atau ada perbedaan, dan kalau ada perbedaan kondisi di tempat mana yang lebih baik". Penelitian ini dilaksanakan di kelas I MIN 3 Kota Medan semester genap tahun ajaran 2019/2020. Penelitian ini dilaksanakan pada bulan Februari April 2020. Arikunto (2013: 173) menyatakan "populasi adalah keseluruhan subjek penelitian". Adapun subjek penelitian ini yaitu siswa kelas $\mathrm{I}^{\mathrm{A}}$ dan $\mathrm{I}^{\mathrm{B}}$ MIN 3 Kota Medan yang berjumlah 50 orang, yaitu kelas IA berjumlah 25 siswa dan IB berjumlah 25 siswa.

Sampel adalah bagian dari populasi yang menjadi data pada penelitian. Menurut Sugiyono (2017: 81) "sampel adalah bagian dari jumlah dan karakteristik yang dimiliki populasi tersebut". Teknik pengambilan sampel pada penelitian ini adalah dengan sampling jenuh. Sampling jenuh adalah teknik penentuan sampel bila semua anggota populasi digunakan sebagai sampel (Sugiyono, 2017: 85) Berdasarkan jumlah populasi tersebut, maka sampel yang diambil penelitian

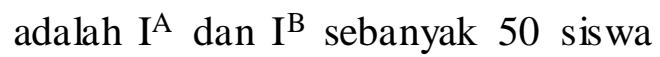
maka sampel yang diambil adalah semua jumlah populasi. Dalam hal ini siswa kelas $\mathrm{I}^{\mathrm{B}}$ yang berjumlah 25 siswa menjadi kelas eksperimen I dan kelas $\mathrm{I}^{\mathrm{A}}$ yang berjumlah 25 siswa menjadi kelas eksperimen II. Adapun desain penelitian ini menggunakan desain penelitian The Static Group Pretest Post-test Design yang melibatkan dua kelas yang diberi perlakuan yang berbeda. Untuk mengetahui hasil belajar siswa dilakukan dengan tes pada kedua kelas sebelum dan sesudah diberi perlakuan.

\section{Tabel 1. Desain Penelitian}

\begin{tabular}{c|c|c|c}
\hline Sampel & $\begin{array}{c}\text { Pre- } \\
\text { test }\end{array}$ & Perlakuan & $\begin{array}{c}\text { Post- } \\
\text { test }\end{array}$ \\
\hline $\mathrm{A}$ & $\mathrm{O}_{1}$ & $\mathrm{X}_{1}$ & $\mathrm{O}_{2}$ \\
\hline $\mathrm{B}$ & $\mathrm{O}_{3}$ & $\mathrm{X}_{2}$ & $\mathrm{O}_{4}$ \\
\hline
\end{tabular}

(Sukmadinata, 2011: 209)

Observasi yang digunakan dalam penelitian ini adalah observasi sistematis, yaitu kegiatan yang dilakukan pengamat dengan menggunakan pedoman sebagai instrumen pengamatan. Pedoman berisikan item-item tentang kejadian atau tingkah laku yang digambarkan akan terjadi (Arikunto, 2013 : 272). 
Teknik ini digunakan untuk mengumpulkan data aktivitas guru dan siswa selama proses pembelajaran dengan menggunakan media augmented reality dan media gambar di MIN 3 Kota Medan. Instrumen penelitian yang digunakan untuk mengumpulkan hasil belajar siswa adalah tes hasil belajar pada materi benda hidup dan tak hidup yang terdiri dari 30 soal. Sesuai dengan design penelitian yang digunakan dalam penelitian ini yaitu design The Static Group Pretest Posttest Design maka tes yang dilaksanakan juga menggunakan pretest dan post-test. pemberian pretest dan post-test pada siswa akan menuntun siswa kepada tahap-tahap perkembangan kognitif dalam memahami materi atau bahan pelajaran dengan baik dalam proses belajar.

Sejalan dengan teori Piaget yang menyatakan bahwasannya proses belajar siswa mengalami asimilasi dan akomodasi. Pretest memiliki persiapan akan bahan yang akan diterima siswa sehingga proses penyatuan (asimilasi) bahan yang sudah dikuasai siswa dengan bahan yang baru diajarkan dapat membuat perkembangan siswa lebih baik atau terjadi akomodasi (Efendy, 2016: 85). Teknik analisis data yang digunakan adalah analisis perbedaan dengan menggunakan rumus uji-t. Alasan peneliti menggunakan uji-t adalah untuk mengetahui apakah ada perbedaan rata-rata dari sampel yang diambil. Sebelum melakukn uji-t tersebut.

\section{HASIL PENELITIAN DAN PEMBAHASAN}

Instrumen penelitian yang digunakan untuk mengumpulkan data hasil belajar siswa adalah berupa tes soal pilihan bergandaSebagai alat ukur, tes hasil belajar siswa harus memenuhi syarat memiliki alat ukur yang baik. Alat ukur pengumpulan data berupa tes harus memenuhi 4 syarat yaitu validitas, reliabilitas, tingkat kesukaran dan daya pembeda. Uji coba instrumen dilakukan di MIN 3 Kota Medan dengan jumlah siswa 30 dan jumlah soal sebanyak 30 butir. Uji validitas dalam penelitian ini digunakan untuk mengukur valid atau tidaknya soal. Soal diujikan kepada siswa-siswa yang sebelumnya telah mempelajari materi Benda Hidup dan Tak Hidup. Berdasarkan hasil akhir yang didapat pada perhitungan validitas dengan menggunakan rumus product moment diperoleh data 22 soal yang valid, dimana $r_{\text {hitung }}>r_{\text {tabel }}$ dengan taraf signifikan 0,05.

Nomor soal-soal yang valid dari 30 soal yakni terdapat pada nomor $1,4,6,7,8,9,11,12,13,14$, 16, 17, 20, 21, 22, 23, 24, 25, 27, 28, 29, 30. Sedangkan untuk soal yang tidak valid berjumlah 8 dari 30 soal yaitu pada soal nomor 2, 3, 5, 10, 15, $18,19,26$. Perhitungan validitas bisa dilihat pada lampiran 15 dan 16 . Berikut tabel rekapitulasi dan tabel taksonomi bloom dari setiap soal yang sudah valid. 
Tabel 2. Kategori Soal Taksonomi Bloom Untuk Soal yang Valid

\begin{tabular}{|c|c|c|c|c|c|}
\hline \multirow{2}{*}{$\begin{array}{c}\text { Indikator } \\
\text { Pembelajaran }\end{array}$} & \multicolumn{4}{|c|}{ Kemampuan Kognitif } & \multirow{2}{*}{$\begin{array}{c}\text { Jumlah } \\
\text { Soal }\end{array}$} \\
\hline & C1 & $\mathrm{C2}$ & $\mathrm{C3}$ & $\mathrm{C4}$ & \\
\hline Benda hidup & $6,7,30$ & $\begin{array}{c}14,16 \\
4\end{array}$ & 24 & - & 7 \\
\hline Benda tak hidup & 13 & $\begin{array}{c}17 \\
27,8\end{array}$ & $\begin{array}{l}21,22 \\
23,25\end{array}$ & - & 8 \\
\hline Ciri-ciri benda hidup & 1,9 & 28 & - & 11 & 4 \\
\hline Ciri-ciri benda tak hidup & - & $\begin{array}{c}12,29, \\
20\end{array}$ & - & - & 3 \\
\hline \multicolumn{5}{|c|}{ TOTAL SOAL } & 22 \\
\hline
\end{tabular}

Sejalan dengan teori yang dikatakan oleh Munadhi (2008: 24) bahwasannya hasil belajar memiliki faktor instrumental yang dapat memengaruhi hasil belajar yaitu salah satunya sarana prasarana sekolah dimana media merupakan salah satu sarana dan prasarana sekolah. Maka dari itu penulis memilih media augmented reality dan media gambar dimana kedua media tersebut memiliki kelebihan yaitu dapat memperjelas sebuah materi sehingga siswa dapat memahami materi dengan baik. Dengan begitu siswa dapat dengan lancar menjawab pertanyaan yang diberikan oleh guru. Penelitian relevan (bab 2 halaman 23) juga membuktikan bahwasannya media augmented dan media gambar memengaruhi hasil belajar siswa kearah yang lebih baik. Perbedaan penelitian relevan dengan penelitian yang penulis lakukan yaitu terletak pada subjek penelitian dan materi pembelajaran. Dari penelitian ini penulis membuktikan bahwasaanya Media dan citra augmented reality dapat diterapkan pada benda hidup dan tak hidup.

\section{Pembahasan}

Penelitian ini bertujuan untuk mengetahui bagaimana pengaruh media augmented reality dengan media visual terhadap hasil belajar yaitu dengan cara melakukan pretest dan posttest. Sejalan dengan teori Piaget (Efendy 2016: 85) menyatakan bahwasannya proses belajar siswa mengalami asimilasi dan akomodasi. "Pretest memiliki persiapan akan bahan yang akan diterima siswa sehingga proses penyatuan (asimilasi) bahan yang sudah dikuasai siswa dengan bahan yang baru diajarkan dapat membuat perkembangan siswa lebih baik atau terjadi akomodasi". Efendy (2016 : 86) juga menyatakan "post-test disetiap akhir pertemuan akan sangat membantu siswa dalam mengambil kesimpulan terhadap pelajar yang telah diikutinya". Dari hasil pretest dan post-test diketahui bahwasaannya kedua media memberikan dampak baik terhadap hasil belajar siswa. Dari hasil pretest dan post-test diketahui juga bahwasannya media augmented reality memberikan pemahaman yang 
lebih baik kepada siswa mengenai materi benda hidup dan tak hidup.

Setelah mengetahui hasil belajar siswa maka dilakukanlah uji normalitas, homogenitas dan hipotesis. Dari uji normalitas dan homogenitas kedua kelas berditribusi normal dan homogen. Lalu dilakukanlah pengujian hipotesis dengan uji-t dan taraf signifikan 0,05 untuk melihat perbandingan hasil belajar kedua kelas. Hasil yang diperoleh adalah 7,009 pada $t$ tabel 1,676 atau 7,009 > 1,676. Artinya terdapat perbedaan hasil belajar siswa yang besar ketika menggunakan media augmented reality dan media gambar. Kelas IMIN 3 Saat hasil belajar menggunakan media augmented reality lebih unggul dari media gambar untuk materi hidup dan tak hidup dalam meditasi. Lalu dari hasil observasi, kepercayaan diri siswa lebih antusias di kelas eksperimen I dibanding dengan eksperimen II. Ditunjukkan dari antusias siswa dalam memaparkan LKPD di depan kelas. Hasil rata-rata nilai observasi siswa kelas eksperimen I yaitu 99,56 dan eksperimen II yaitu 97,8 yang tergolong sangat baik. Untuk hasil observasi guru, nilai yang didapat di kelas eksperimen I yaitu 97,6 dan eksperimen II yaitu 100. Kedua nilai tersebut tergolong kriteria sangat baik.

Pada penelitian ini terdapat kelemahan dalam pembuatan augmented reality. Pembuatan augmented reality ini memakan waktu cukup lama dikarenakan penulis baru berkecimpung dalam pembuatan augmented reality sehingga butuh waktu untuk memahami setiap item dalam aplikasi Unity, yaitu aplikasi yang dapat membuat augmented reality. Lalu pada augmented reality yang penulis buat hanya sedikit objek benda hidup dan benda mati. Maka dari itu solusi untuk peneliti lainnya jika tidak ingin memakan waktu yang cukup lama dalam pembuatan augmented reality, saat ini sudah tersedia di playstore aplikasi augmented reality yang bernama aurasma. Peneliti lainnya bisa menggunakan augmented reality secara instan dengan aplikasi aurasma. Jika ingin membuat sendiri aplikasi augmented reality maka perbanyaklah objek dalam aplikasi augmented reality.

\section{SIMPULAN}

Berdasarkan hasil penelitian yang diperoleh dari analisis dan pengujian hipotesis, maka dapat ditarik kesimpulan sebagai berikut: Rata-rata hasil belajar siswa pada kelas eksperimen I yang telah diberikan treatment dengan media augmented reality adalah 91,4 yang tergolong sangat baik. Rata-rata hasil belajar siswa pada kelas eksperimen II yang telah diberikan treatment dengan media gambar adalah 78,6 yang tergolong cukup baik.

Berdasarkan hasil perhitungan uji$\mathrm{t}$, thitung > ttabel $=7,009>1,676$ maka H0 ditolak dan Ha diterima yang artinya penggunaan media augmented reality dan gambar untuk 
hidup dan I MIN 3 benda mati di kota Medan.

\section{DAFTAR RUJUKAN}

Akbar, Ahmad Ali. 2018. Pengaruh Penggunaan Media Gambar Terhadap Hasil Belajar Bahasa Indonesia Pada Siswa Kelas IV Sekolah Dasar. Jurnal Riset Pendidikan Dasar, (Online), Vol 1 No.1

Angkowo. R dan A. Kosasih. 2007. Optimalisasi Media

Pembelajaran. Jakarta : Grasindo

Arifitama, Budi. 2017. Panduan

Mudah Membuat Augmented Reality. Yogyakarta: ANDI OFFSET

Arikunto, Suharsimi. 2013. Prosedur Penelitian : Suatu Pendekatan Praktik. Jakarta : Rineka Cipta

Arikunto, Suharsimi. 2016. DasarDasar Evaluasi Pendidikan. Jakarta : Bumi Aksara

Arsyad, Arshad. 2017. Media Pembelajaran. Jakarta: Rajawali Pers

Effendy, Ilham. 2016. Pengaruh Pemberian Pretest dan Post-test Terhadap Hasil Belajar Mata Diklat HDW. DEV.100.2.A Pada Siswa SMK Negeri 2 Lubuk Basung. Jurnal Ilmiah Pendidikan Teknik Elektro, (Online), Vol. 1, No. 2

Elpis. 2017. Penggunaan Media Gambar Untuk Meningkatkan Hasil Belajar Ips Siswa Kelas VI SDN 010 Jaya Mukti. Jurnal Primary, (Online), Vol. 6 No.2
Jihad,Asep. 2012. Evaluasi Pembelajaran. Yogyakarta: Multi Pressindo

Latip, Asep Ediana. 2018. Evaluasi Pembelajaran di SD dan MI. Bandung: Remaja Rosdakarya

Munadhi, Yudhi. 2008. Media Pembelajaran: Sebuah Pendekatan Baru. Jakarta: Gaung Persada

Munir. 2017. Pembelajaran Digital. Bandung: Alfabeta

Nasriah \& Dedy Huzrizal Syah. 2013. Konsep Dasar Paud. Medan: Unimed Press

Prasetya, Sukma Perdana. 2014. Media Pembelajaran Geografi. Yogyakarta: Ombak

Purnamasari, Dian. 2016. Pengaruh Penerapan Media Augmented Reality Berbasis Discovery Learning Terhadap Hasil Belajar Pada Materi Darah. Jurnal BioPedagogi, (online), Vol. 5 No.2.

Rambe, Muhammad Fakri. 2019. Perbedaan Hasil Belajar IPA Dalam Penerapan Model Pembelajaran Kooperatif Tipe Two Stay Two Stray Dengan Model Pembelajaran Kooperatif Tipe Scramble Di Kelas V SD Negeri 101799 Deli Tua Tahun Ajaran 2018/2019. Medan: Universitas Negeri Medan. Skripsi

Ramdhan, Khemal Rizky, dkk. 2017. Aplikasi Media Pembelajaran Tulang Manusia Menggunakan Augmented Reality (AR) Berbasis Android. Jurnal Teknik Informatika dan Sistem informasi, (online), Vol. 3 No.3 
Sabri, Ahmad. 2010. Strategi Belajar Mengajar. Ciputat: Ciputat Press Saputri, Dian Syahfitri Chani. 2017. Penggunaan Augmented Reality untuk Meningkatkan Penguasaan Kosa Kata dan Hasil Belajar. JUTISI, (Online), Vol 6 No.1

Sinyanyuri, Sonya \& Lubna Assagaf. 2017. Tema 7 Benda, Hewan dan Tanaman di Sekitarku. Jakarta: Kementerian Pendidikan dan Kebudayaan.

Sudjana, Nana. 2010. Penilaian Hasil Proses Belajar Mengajar. Bandung : Remaja Rosdakarya Sudjana, Nana. 2016. Metoda Statistik. Bandung: Tarsito Bandung

Sukmadinata. 2011. Metoode Penelitian Pendidikan. Bandung: Remaja Rosdakarya

Sugiyono. 2017. Metode Penelitian Kuantitatif, Kualitatif, dan $R \& D$. Bandung: Alfabeta

Yanti, Nirma, dkk. 2018. Pengaruh Penggunaan Media Gambar Terhadap Kemampuan Menulis Puisi Rakyat Siswa Kelas VII SMP Negeri 6 Kota Jambi Tahun Ajaran 2017/2018. Jurnal Ilmiah Pendidikan Bahasa dan Sastra Indonesia, (Online), Vol. 2 No.2 